\title{
CUIDADO COMPARTILHADO: UMA PERSPECTIVA DE CUIDAR DO IDOSO FUNDAMENTADA NA EDUCAÇÃO EM SAÚDE
}

\author{
Maria Luiza de Oliveira Teixeira', Márcia de Assunção Ferreira²
}

\begin{abstract}
${ }^{1}$ Doutora em Enfermagem. Professor Adjunto do Departamento de Enfermagem Fundamental da Escola de Enfermagem Anna Nery (EEAN) da Universidade Federal do Rio de Janeiro (UFRJ). Rio de Janeiro, Brasil. E-mail: mlot@uol.com.br

${ }^{2}$ Doutora em Enfermagem. Professor Titular do Departamento de Enfermagem Fundamental da EEAN/UFRJ. Pesquisadora do CNPq. Rio de Janeiro, Brasil. E-mail: marciadeaf@ibest.com.br
\end{abstract}

RESUMO: Pesquisa convergente-assistencial que objetivou identificar os saberes e práticas dos acompanhantes de idosos hospitalizados sobre os cuidados na prevenção e tratamento de úlceras por pressão, integrá-los a um plano de cuidados e discutir sua efetividade. O referencial teórico abordou a cultura de práticas e saberes sobre o cuidado em saúde e suas relações com a educação em saúde. Participaram 19 acompanhantes de idosos hospitalizados. Realizaram-se entrevistas em grupo e individuais, e observação participante. A análise foi de conteúdo temático. No intercâmbio de saberes com a pesquisadora, os sujeitos elaboraram, implementaram e avaliaram um plano de cuidados de prevenção e tratamento das úlceras de pressão. Refletiram criticamente e participaram do cuidado. Concluiu-se que não basta reconhecer a existência do sistema profissional e popular de saúde, mas propor estratégias para um cuidado congruente às reais necessidades de clientes e acompanhantes tornando-os parceiros. A dialogicidade propiciou a construção compartilhada do cuidado.

DESCRITORES: Enfermagem. Educação em saúde. Idoso. Cuidados de enfermagem. Acompanhantes de pacientes.

\section{SHARED CARE: A VISION OF ELDERLY CARE BASED ON HEALTH EDUCATION}

\begin{abstract}
This research, which followed the convergent-assistance method, aimed to identify the knowledge and practices of hospitalized elderly companions concerning pressure ulcer prevention and treatment, to integrate them in a care plan, and to discuss its effectiveness. The theoretical referential outlined the cultural practices about health care and their relation with health education. Nineteen companions participated. Group and individual interviews, as well as participant observation was carried out. Analysis was done by thematic content. In knowledge exchange with the researcher, the individuals developed, implemented, and evaluated a care plan for pressure ulcer prevention and treatment. They reflected critically and participated in the care. The conclusion was that it is not enough to merely recognize the existence of a professional and a popular health system, but it is necessary to propose strategies for congruent care for the real needs of clients and companions, making them partners in care. The dialogue allowed for the shared development of care.
\end{abstract}

DESCRITORES: Nursing. Health education. Aged. Nursing care. Patient escort service.

\section{EL CUIDADO COMPARTIDO: UNA PERSPECTIVA DE CUIDAR DEL ANCIANO BASADA EN LA EDUCACIÓN EN SALUD}

RESUMEN: Investigación convergente asistencial con el objetivo de identificar los conocimientos y las prácticas de los acompañantes de los ancianos hospitalizados acerca de los cuidados con la prevención y tratamiento de úlceras por presión, integrarlos a un plan de cuidados y discutir su efectividad. En el marco teórico se abordó la cultura de las prácticas y conocimientos sobre el cuidado en salud y sus relaciones con la educación en salud. Participaron diecinueve acompañantes de ancianos hospitalizados. Se realizaron entrevistas en grupo e individuales, y observación participativa. Se analizó el contenido temático. En el intercambio de conocimientos con la investigadora, los sujetos elaboraron, implementaron y evaluaron un plan de cuidados de prevención y tratamiento de las úlceras por presión. Reflexionaron críticamente y participaron del cuidado. Se concluyó que no basta reconocer la existencia del sistema profesional y popular de salud, sino proponer estrategias para un cuidado congruente con las reales necesidades de los clientes y acompañantes tornándolos copartícipes. La dialogicidad propició la construcción compartida del cuidado.

DESCRIPTORES: Enfermería. Educación en salud. Anciano. Atención de enfermería. Acompañantes de pacientes. 


\section{INTRODUÇÃO}

O objeto centra-se nos saberes dos acompanhantes de idosos hospitalizados sobre os cuidados na prevenção e tratamento de Úlcera por Pressão (UP). A questão situa-se na inserção do acompanhante no hospital que, na maioria das vezes, ocorre de acordo com a lógica do modelo biomédico, na qual seus saberes e práticas de cuidado não são considerados ou valorizados no contexto geral da assistência.

Ainda que haja iniciativas de inseri-los no cuidado, o modelo é verticalizado, não viabilizando a sua participação com autonomia, já que esta exige tomada de consciência da situação. O princípio da integralidade preconiza ações de prevenção e cura sem compartimentalização e, ainda, o protagonismo do cliente toma vulto nas ações, uma vez que não se pode conceber cidadania sem participação ativa nos processos decisórios. Contudo, se levarmos em conta que em um cenário de cuidado há prevalência de um determinado tipo de saber sobre outro, isto pressupõe condições desiguais de participação daqueles detêm tais saberes. A fim de garantir a respeitabilidade à cultura de cuidados dos clientes-cidadãos, faz-se necessário mudar a lógica que sustenta a assistência à saúde, principalmente no campo hospitalar.

Assim, o pressuposto desta pesquisa é que estratégias de educação em saúde podem ser implementadas no cenário hospitalar com vistas à inclusão e participação do acompanhante no cuidado ao idoso hospitalizado. Os objetivos são: conhecer os saberes e práticas de acompanhantes de idosos hospitalizados sobre a prevenção e tratamento das UP; discutir a efetividade de um plano de cuidados de prevenção e tratamento considerando a integração de saberes e práticas de acompanhantes de idosos hospitalizados.

Aplicaram-se os conceitos de Freire ${ }^{1}$ e Leininger ${ }^{2}$ no que tange ao contexto cultural de práticas e saberes sobre o cuidado em saúde e suas relações com a educação em saúde e o cuidado de enfermagem.

O debate teórico sustentou-se na valorização da cultura dos acompanhantes de idosos hospitalizados envolvidos no cuidado, pois tanto na prática educativa de Freire, quanto nas práticas de cuidado de Leininger, o reconhecimento e o respeito à identidade cultural são importantes.

\section{METODOLOGIA}

Pesquisa qualitativa de abordagem convergente-assistencial, pois privilegiou o envolvimento e a inclusão dos sujeitos pesquisados no processo da pesquisa articulado à assistência. ${ }^{3}$

Os sujeitos foram escolhidos a partir da aplicação dos seguintes critérios de inclusão: no período de execução da pesquisa: deveriam estar na condição de acompanhantes participando ativamente do processo de hospitalização do idoso, em caráter voluntário ou não, podendo ser do sexo masculino ou feminino. Desta forma, participaram 19 acompanhantes de idosos internados na clínica médica de um Hospital Universitário público federal do município do Rio de Janeiro-RJ. Os dados foram produzidos no período de junho a julho de 2007, com aplicação das técnicas de entrevistas individuais e em grupo, seguindo um roteiro semi-estruturado com perguntas abertas sobre o conhecimento dos acompanhantes sobre as UPs e os cuidados para prevení-las e tratá-las, e de observação participante, com aplicação de um roteiro cujos tópicos permitiram captar a participação dos acompanhantes no cuidado e suas formas de lidar com o idoso e com a equipe de enfermagem.

Uma vez que a pesquisa teve como linha condutora os saberes e práticas de cuidado dos acompanhantes de idosos hospitalizados sobre determinado tema, foi preciso conhecer as características gerais dos participantes diretos (acompanhantes) e indiretos (idosos). Isto foi feito a partir da aplicação de um instrumento sobre o perfil sócio-demográfico e da situação de saúde atual do idoso. Em seguida, aplicou-se a técnica de entrevista sobre o tema prevenção e tratamento de UP. O objetivo foi estabelecer o diálogo com os sujeitos sobre seus saberes e práticas e intercambiálos com os da pesquisadora, fazendo convergir a etapa de produção de dados da pesquisa com o momento da assistência, no intercâmbio de saberes. No âmbito das discussões com os acompanhantes, caracterizou-se a problematização e foram elaboradas as propostas de cuidados a serem aplicados pelos acompanhantes na prevenção e tratamento de UP. No decorrer da implementação dos cuidados planejados, aplicou-se a técnica de observação participante, com vistas a captar os dados que serviram de base para análise da efetividade da estratégia de educação em saúde implementada no processo da pesquisa. Os dados foram gerados em conjunto, pela observação da pesquisadora e pela interpretação dos sujeitos para que os mesmos 
protagonizassem a avaliação. Ao final, houve uma discussão sobre os dados observados e todos teceram considerações sobre o trabalho. Para análise do material, os textos foram organizados seguindo-se o preconizado pela análise temática de conteúdo.

Em atendimento à Resolução No 196/96 do Conselho Nacional de Saúde, o projeto de pesquisa foi aprovado no Comitê de Ética em Pesquisa do Hospital Universitário Clementino Fraga Filho da Universidade Federal do Rio de Janeiro, protocolo $\mathrm{N}^{\mathrm{o}}$ 002/07. O Termo de Consentimento Livre e Esclarecido foi assinado por todos os sujeitos. $\mathrm{O}$ anonimato foi garantido pela identificação alfanumérica dos depoimentos, cuja letra A significa acompanhante, seguida de números arábicos sequenciais. Um idoso estava sendo assistido por três acompanhantes. Neste caso, estes foram identificados acrescentando as letras b e c à sequência da letra A e ao número arábico. Após esta identificação, acrescentou-se o tipo de vínculo que o acompanhante mantinha com o idoso.

\section{RESULTADOS E DISCUSSÃO}

Os acompanhantes, em sua maioria, são cuidadores leigos, ${ }^{4}$ nesse sentido, integram o que se pode chamar de sistemas populares de cuidado, de caráter informal, em contraponto ao sistema profissional de cuidados (formal). ${ }^{2}$ Quando os acompanhantes se encontram no espaço da rede formal, perdem sua autonomia e capacidade decisória, pois a organização do cuidado segue os cânones científicos e tecnológicos, com normas e rotinas que toda instituição exige.

Neste ambiente, cuidar do idoso significa obedecer a regras e aceitar as condições impostas, como espectador, pois, agora aqui no hospital não tem jeito, tem que ser o que o hospital manda, tem que obedecer a rotina do hospital. Em casa a gente pode fazer diferente (A3 - cunhada).

As relações culturais estabelecidas entre os profissionais e os acompanhantes, que também cuidam e se envolvem com o idoso internado, merecem destaque. A assistência sustentada no modelo tradicional funciona como o opressor que normatiza e prescreve condutas, e o acompanhante, ao aceitá-las passivamente, não negocia, acomoda-se assumindo a posição de oprimido.

Todo homem que não tem a consciência de suas possibilidades, vive adaptado, imerso na engrenagem da estrutura dominante. Também é aquele que hospeda o opressor dentro de si, assumindo uma atitude fatalista de aceitação de sua sina. ${ }^{5}$
Estar sob o domínio da instituição hospitalar leva tanto a equipe quanto o acompanhante a se verem em padrões seletivos e normativos, que mantém a fronteira entre o sistema popular e o profissional de cuidado. No entanto, acompanhar um idoso no hospital pode também ser um momento destinado a aprender como lidar com ele em casa, quando lhes é dada a oportunidade de participação nos cuidados. A acompanhante A11 deixa isto claro em seu depoimento e reforça a participação em cuidados diários como o banho.

Eu sinto assim, que a gente dá um pouco do nosso carinho, do nosso apoio, e principalmente ter informações do médico e aprender a lidar com eles. No caso ele fez uma cirurgia e eu tinha que aprender como agir com ele em casa. E eu não fico aqui à noite só fico durante o dia que é para participar do banho, medicação, porque para eu ir para a casa eu tenho que aprender a fazer direitinho as coisas (A11- nora).

Esse depoimento nos remete a uma questão culturalmente formada que diz respeito ao fato de considerar o médico como o detentor do saber e o único capaz de informar e orientar sobre o cuidado. Em nome da hegemonia do saber médico os outros profissionais são ignorados. A possibilidade da construção compartilhada do saber tendo esta barreira cultural se torna mais difícil, não só pelo fato do senso comum ser marginalizado pelos profissionais, como também, pela dificuldade do acompanhante perceber que a sua cultura também produz saber e que é possível "que haja uma relação simbiótica entre os dois tipos de conhecimento, o científico e o popular [...] sem a sobreposição de um saber sobre o outro, mas sim reconhecendo as possibilidades e limitações de cada um" .6:507

Esta participação pode conduzi-lo à construção do cuidado congruente e do cuidado compartilhado. Nesta pesquisa, acessar os saberes dos sujeitos sobre os cuidados relacionados à pele é crucial, pois pode influenciar no cuidado ao idoso. Os acompanhantes verbalizaram seus conhecimentos de forma simples e limitada, indicando que têm certas noções sobre o tema. Para trazer à tona as concepções que o acompanhante possui sobre UP, utilizamos, inicialmente, o seguinte questionamento como pergunta chave: se o idoso ficar muito tempo deitado, o que pode acontecer na pele? Ao responder a este questionamento ficou evidenciada a experiência vivida pelos acompanhantes sobre este problema, à luz do senso comum que se apresenta como uma forma de conhecimento efetivamente prático, elaborado a partir das ações do cotidiano. O caráter espontâneo e prático que 
caracteriza o pensamento do senso comum ${ }^{7}$ pode ser evidenciado no depoimento seguinte.

Causa uma ferida, e até um buraco. Eu mesma já vi lá no hospital. Quando viraram a senhora do lado, tinha um maior "buracão". Deu ferida e formou um buraco (A11 - nora).

Em outros depoimentos vemos a incidência do conhecimento técnico-científico da saúde na descriminação da lesão: sim, a experiência diz que é escara (A2 - cunhado). As escaras vão aparecer normal (A16 - sobrinha).

Os saberes da população são elaborados sobre a experiência concreta, a partir de suas vivências, diferentemente daquela vivida pelo profissional. Partir do saber do outro não significa ficar preso a ele, mas considerar que seu conteúdo possa servir de base para melhor conhecer o sujeito. Nesse sentido, a eficiência no processo educativo depende da capacidade do educador em conseguir entender a leitura do mundo feita pelo educando e, a partir dessa leitura, ampliar o seu conhecimento, levando o educando a ter uma visão mais crítica. ${ }^{5}$

Vale ressaltar que a noção que o acompanhante tem da UP pode influenciar no cuidado ao idoso. Isto significa que a enfermeira precisa desenvolver habilidades para ouvir as narrativas dos acompanhantes, com uma escuta qualificada, o que implica em lembrar que a narração de um fato pode modificar a maneira de encará-lo e agir sobre a situação. Afinal, aprender a ouvir é uma habilidade fundamental na educação em saúde e no cuidado de enfermagem. ${ }^{9}$

A maneira peculiar dos acompanhantes verbalizarem seus saberes demonstra que aspectos relacionados ao cuidado à saúde tendem a constituir uma linguagem socialmente organizada para descrever o problema, advindo de seu universo vocabular que também mostra termos técnico-científicos. O conhecimento popular é socialmente elaborado e compartilhado, constituído a partir das nossas experiências do dia a dia, como também pelas informações que são obtidas através de diversos meios de comunicação, daí a explicação da presença de termos científicos nos depoimentos dos sujeitos. Nesse sentido, ao tempo em que o acompanhante esforça-se para entender o processo de desenvolvimento da enfermidade à luz de seu conhecimento prévio por comparações, semelhanças e diferenças, também incorpora novos saberes que contribuem para a (re)construção de seu conhecimento.

Essa ferida é uma coisa estranha mesmo. Parece que existe alguma coisa que vai corroendo [...] ali como se fosse um ácido que tivesse jogado na pele da pessoa! Vai aumentando... Então a ferida é complicada (A10 - nora).

A linguagem dos acompanhantes é constituída de um vocabulário próprio, por vezes metafórico. Esta linguagem, popular, tem uma riqueza simbólica que traduz o significado pessoal e coletivo que as palavras trazem do mundo. A leitura do mundo é um processo próprio e acessível a todos, portanto, a linguagem não pode estar separada de seu significado social e cultural. Por estes motivos deve ser considerada no processo de educação em saúde junto aos acompanhantes dos idosos.

É importante para o cidadão comum ter noções básicas sobre a saúde. Nos cuidados com a pele, em especial das UPs, é necessário que algumas noções sejam mais detalhadas para que o acompanhante saiba o porquê de determinadas ações para promover a prevenção e futuramente o tratamento do problema, e também para levá-lo à construção, (des) construção e (re)construção do conhecimento. Com estas considerações, no diálogo com os acompanhantes, iniciou-se o processo de conscientização com a reflexão a partir do debate sobre o tema. Constatouse que no momento em que se dá oportunidade de diálogo, compartilha-se o conhecimento.

Escaras, antigamente se chamavam escaras, hoje mudaram a terminologia e são chamadas também de úlceras por pressão (Pesquisadora). Hum... úlceras por pressão. Porque fica pressionando né? Se ficar muito tempo deitado também acho que vem a coisa da pneumonia, sei lá, porque o pulmão fica muito, muito abafado. Aí eu boto sempre ele sentado (A7 - esposa).

Houve por parte da acompanhante uma reflexão, pois ela mesma associou o nome atual, úlcera por pressão, com a causa, ou seja, a pressão, e foi além, associando a pressão do leito no tórax à pneumonia, mostrando a lógica que conforma a construção do conhecimento do senso comum, pois se a pressão sobre a pele a danifica, a pressão sobre o tórax irá danificar os pulmões. No entanto, esta relação direta por associação de semelhanças e diferenças nem sempre se aplica às enfermidades/situações problemas. E é exatamente por isso que mais uma vez reitera-se a importância de se criar espaços de diálogo e intercâmbio de saberes entre os profissionais e acompanhantes, pois no momento em que se dá a oportunidade do diálogo, o conhecimento é compartilhado.

A partir de então, passou-se a discutir sobre o que fazer para prevenir o aparecimento de tais ferimentos, feridinhas e escaras. Com a reflexão iniciada a partir do tema gerador, os acompanhantes 
conseguiram entender que o cuidado inicial para a prevenção das UPs é eliminar a principal causa: a pressão. A partir daí torna-se mais fácil derivar as estratégias de cuidado para a prevenção: a movimentação e a mudança de posição.

É, escaras. Ele pode evitar essas feridas sempre movimentando. Graças a Deus não é o caso dele, porque ele não é um paciente totalmente acamado. Entendeu? Ele vive em movimento, senta, levanta um pouquinho, entendeu? (A6 - filha).

Alguns acompanhantes acrescentaram o intervalo de tempo para que a mudança de decúbito ocorra, e outros, em suas falas, veicularam os artefatos empregados nas instituições e que circulam nos diálogos do meio profissional no conjunto de medidas que viabilizam o alívio da pressão. Isto se dá pelo fato da cultura popular incorporar elementos do meio científico, que ao se converterem em senso comum, penetram em seu meio.

Os acompanhantes citaram alguns dos artefatos utilizados no meio científico: a utilização de tecnologias de cuidado como colchão caixa de ovo e colchão e almofadas d'água (tipo bóia). No entanto, estas duas últimas tecnologias não são mais indicadas na prevenção e tratamento das UPs. ${ }^{10} \mathrm{O}$ fato de ainda estarem presentes nos depoimentos dos acompanhantes se deve a experiências vividas anteriormente ou oriundas de informações de profissionais de saúde com conhecimento não atualizado sobre o tema. Disto decorrem duas questões: a importância de o profissional conhecer os saberes dos acompanhantes e promover o debate para que eles tenham a oportunidade de atualizar o conhecimento e entendam os porquês de determinados cuidados, antes prescritos, não se aplicarem mais à prática; e a necessidade de atualização técnico-científica do conhecimento pelo profissional. É importante debater com as pessoas sobre esta peculiaridade do conhecimento científico, ou seja, a de não ser absoluto e nem definitivo.

Então, a gente tem que estar virando pelo menos de duas em duas horas. Usar colchão caixa de ovo e bóia tipo de praia para colocar nessa parte aqui [apontou para a região sacra] e no ombro, virar de um lado para o outro (A2 - cunhado).

Sei, a escara né? A gente até comprou o colchão caixa de ovo, e todo dia eu brigo com ele para ele sair da cama um pouco. O que me tranquiliza é que ele levanta para ir ao toalete, e todo esse tempo, eu consegui fazer ele sair para andar uma vez só (A1 - filho).

A mudança de decúbito, apesar de ser a mais difundida, não é a única medida preventiva voltada para as UPs, outros cuidados também são importantes. Por isso, os acompanhantes, durante a discussão, foram apresentando os demais cuidados para prevenção, como aplicação de hidratante, manter boa higiene, não deixar o idoso ficar molhado, trocar as fraldas, esticar bem o lençol. Outros foram acrescentados pela pesquisadora após a reflexão por parte do acompanhante como: a colocação de travesseiros entre as pernas com vistas a apoiar o corpo durante a mudança de decúbito.

Os cuidados apresentados pelos acompanhantes se caracterizam como cuidados fundamentais, baseados nos princípios de higiene, de execução diária, que muitos deles só conseguiram associar à prevenção da úlcera por pressão durante o processo de reflexão. Inclusive, uma das acompanhantes, após este processo, se referiu a estes cuidados como: cuidados que ninguém dá nada por eles (A6 - filha), contudo muito importantes e que fazem a diferença no resultado final. Com isso, também foi possível mais uma vez resgatar experiências vividas e refletir sobre elas, pois a questão da higiene foi muito destacada pelos acompanhantes como cuidado preventivo da UP: em primeiro lugar a higiene, para estar sempre limpinho. A roupa de cama limpinha (A7 - esposa).

Com relação ao tratamento das UPs, os acompanhantes, representantes do sistema popular de saúde, trazem uma série de saberes e práticas oriundos do âmbito familiar repassados entre as gerações. Uma destas práticas está relacionada com o uso de ervas para o tratamento de feridas. No hospital o acompanhante não utiliza esse recurso, mas é importante fazer este levantamento, pois em casa o mesmo poderá lançar mão para o tratamento, como referiu o acompanhante A2. Em seu depoimento informou que já cuidara de sua sogra em casa e que a mesma era portadora de UP, e para o tratamento utilizava casca de aroeira e casca de caju.

Agora é aquele negócio que eu falo também, [...] sempre usava muito dois "matos" chamados casca de aroeira e casca de caju. Aquilo é excelente, cura qualquer ferida de dentro para fora e depois não fica nem a cicatriz. A casca de caju e aroeira a gente ferve, depois de ferver côa bem para não ficar nenhum resíduo. Pode lavar qualquer ferida que vai curar, isso eu garanto mesmo (A2-cunhado).

Mas quando o senhor passava isso, achava que era bom para a ferida. Mas o senhor sabe o que faz na ferida? (Pesquisadora).

Olha não sei te dizer o que ela faz, mas sei que num momento de desespero, porque nós estávamos 
gastando muito e não tínhamos como comprar soro fisiológico, ficava num aperto financeiro tremendo e a única solução naquele momento foi que alguém falou: faz isso, vamos fazer que é bom. Aí nós só usamos isso aí (A2-cunhado).

Neste depoimento, além de informar que já fez uso de erva no tratamento de UP, o acompanhante informou que esta conduta não foi a de primeira escolha. Mesmo conhecedor dos benefícios das ervas, só lançou mão delas por motivos financeiros.

A situação relatada mostra que as ervas, por terem um custo menor ou nulo (as ervas podem ser cultivadas no próprio quintal de casa), são utilizadas como um recurso alternativo ao tratamento alopático/convencional. Recursos não convencionais, neste caso o uso de ervas, utilizados na solução de problemas de saúde, estão extremamente ligados a aspectos sócio-culturais, por isso devem ser considerados relevantes quando se avalia o acompanhante como um indivíduo integral, pertencente a um contexto cultural.

A educação em saúde deve buscar explorar como é elaborado culturalmente a doença, "aprender a relativizar os conhecimentos e permitir trocas possíveis com os sujeitos com os quais se relaciona em seu processo saúde-doença". 11:200

No cuidado, a cultura pode agir de diferentes modos, podendo atuar de forma diversificada e universal orientando decisões e ações. A utilização de ervas no tratamento de feridas é uma prática arraigada à cultura cujo conhecimento é secular.

Percebeu-se uma adequação do uso da planta pelos acompanhantes. Ao acessar este saber torna-se necessário intercambiar os saberes, o uso da planta deve considerar as contra-indicações, o que muitas vezes é negligenciado pelo usuário, pois culturalmente a planta, por ser considerada natural, não faz mal. É o momento de troca entre o saber popular e o científico.

No momento da hospitalização os acompanhantes entram em contato com os saberes do sistema profissional, do saber científico, e pela observação os assimilam, de acordo com o seu arsenal sociocultural e condições de entendimento. Ocorre que, neste processo, muitas vezes replicam as terapêuticas em situações as quais lhe parecem similares e é exatamente aí que pode haver problemas, pois nem sempre as mesmas medidas podem ser aplicadas a toda e qualquer situação. Como resultado deste intercâmbio, os acompanhantes quando falam sobre suas práticas com relação ao tratamento das UPs, mesclam com as práticas do cotidiano hospitalar, ou seja, do conhecimento científico.

Passa medicação, geralmente merthiolate, álcool, também né? Povidine (A1 - filho).

Lavar bem com água, antigamente, colocava mercúrio. Hoje coloco álcool iodado (A5 - filha). O que você acha que o álcool iodado faz? (Pesquisadora). Não é para ajudar a secar? O álcool iodado, o álcool desinfeta, ai misturado com o iodo, além de desinfetar, cicatriza, né?... Acho que é isso! (A5 - filha).

O diálogo permitiu que acompanhante e pesquisadora elaborassem um plano de cuidados voltado para a prevenção e tratamento de UP no ambiente hospitalar, considerando especialmente seus saberes e práticas oriundos de vivências prévias, como também aqueles que são frutos da reflexão realizada durante a coleta de dados.

As principais ações abordadas pelos acompanhantes, que se constituíram no plano de cuidados a ser implementado por eles durante a hospitalização para a prevenção, foram: uso de colchão que reduz a pressão e aumenta o conforto ou almofadas para a cadeira; uso de travesseiros, almofadas para reposicionamento e elevação dos calcâneos; ter escala de horários para movimentação e reposicionamento a cada duas horas, no máximo, quando em repouso no leito e a cada uma hora quando sentado; manter bom alinhamento corporal quando deitado ou sentado; manter toda a roupa de cama limpa e esticada, manter as almofadas limpas; manter pele macia e hidratada com o uso de cremes; não massagear as regiões de proeminências ósseas com avermelhamento da pele; manter a pele limpa e seca; inspecionar as dobras da pele para observar a retenção de umidade; limitar o uso de fraldas com protetores de plásticos ou forros plásticos para incontinência.

Com relação ao tratamento das UPs, alguns aspectos foram levantados durante o diálogo com os acompanhantes, são eles: estar presente durante a realização do curativo, participar do curativo observando o procedimento e as características da úlcera; indagar o profissional sobre a conduta que está sendo implementada.

Tanto o plano para prevenção quanto o para tratamento privilegiaram ações ditas como simples, tais como a observação, a indagação, como ações de cuidado que merecem destaque na assistência ao idoso. Estas ações tornam o acompanhante partícipe do cuidado ao idoso hospitalizado.

O plano elaborado foi o produto que materializou o cuidado compartilhado, pois sua elabora- 
ção se iniciou com o diálogo/reflexão que permitiu que os saberes do sistema profissional e do sistema popular fossem compartilhados. A elaboração do plano de cuidados foi desencadeada pela aprendizagem significativa, processo pelo qual as pessoas precisam estar abertas para aprender a aprender, pois nesta modalidade de aprendizagem, estimula-se o "diálogo com as experiências prévias que cada um tem", '12:238 articulando a novidade a um conhecimento pré-existente de modo que o novo conhecimento faça sentido para o aprendiz.

Na pesquisa, a situação-problema, qual seja, prevenção e tratamento das UPs, se configurou como um contexto significativo. Neste contexto, foi valorizado o que os acompanhantes já sabiam, e através do diálogo/reflexão eles foram mobilizados para aprender novos conhecimentos, sendo estimulados quanto à possibilidade de aplicação de seus saberes no cuidado ao idoso. As motivações, o estabelecimento de relação entre novos conhecimentos e o conhecimento prévio, e a possibilidade de aplicação destes, constituem as características da aprendizagem significativa.

Pode-se fazer uma aproximação desta característica da aprendizagem significativa, que é o último passo da pedagogia problematizadora, ${ }^{1}$ com a Pesquisa Convergente-Assistencial (PCA), adotada neste estudo como método de pesquisa. Em ambas, a prática é valorizada no contexto em que os alunos/acompanhantes estão situados. Na PCA a relação é com a prática assistencial e na aprendizagem significativa ao campo educacional.

Através da execução do plano de cuidados elaborado pelos acompanhantes junto com a pesquisadora, foi possível a aplicação de seus saberes e a mudança de status: de passivo no cuidado para ativo e colaborativo no processo de cuidar, no encontro do sistema popular com o profissional. Ainda mais, destaca-se que a inserção dos acompanhantes de forma ativa levou-os a não se acomodarem, ${ }^{5}$ diante da carência de recursos básicos para cuidar, pois entendendo a importância dos cuidados preventivos, eles se mobilizaram para reverter a situação, intervindo na realidade em prol de sua qualidade, caracterizando o que é problematizar. Na observação participante detectou-se que os acompanhantes estendiam o lençol com frequência. Algumas das acompanhantes (A3, A3b, A5, A15), após o procedimento do banho no leito realizado pela equipe de enfermagem, se dirigiam ao leito, e como se fossem checar o procedimento, esticavam o lençol.
Toda hora que eu mexo nela eu tento puxar, porque sempre solta, mas aí eu sempre puxo, pra não ficar debaixo dela nenhuma dobra. Eu sempre estou puxando o lençol, de noite, quando ela acorda, eu sempre dou uma puxada no lençol (A3 - cunhada).

O cuidado das acompanhantes foi marcado por um processo interativo, onde compartilharam com os idosos o saber relativo a este procedimento, na tentativa de torná-lo menos passivo e mais participativo em seu próprio cuidado.

Nesta situação percebe-se que a interação da pesquisadora com o acompanhante e deste com o idoso, considerando o intercâmbio de saberes culturais, leva-os a se tornarem participativos e promotores de um cuidado diferenciado e congruente. Este foi elaborado a partir da necessidade de troca de conhecimento, de diálogo, de participação.

Durante o diálogo, os acompanhantes deixavam fluir a importância de continuar observando a pele do idoso; no entanto, tomaram ciência de que a qualidade da observação, a partir de então, mudaria. O que antes era feito de forma mais geral, não específica e assistemática, passaria a ser mais bem orientada. Saberiam o que, o porquê e para que observar.

Os acompanhantes ficaram surpresos quando lhes foi apresentado o ato de observar como uma forma de cuidar. O diálogo levou os acompanhantes a identificarem a observação como um cuidado preventivo e curativo, de detecção de situações que necessitam de intervenções.

O plano de cuidados elaborado em conjunto com os acompanhantes continha ações que poderiam ser realizadas por eles de forma independente. $\mathrm{O}$ que se verificou, no entanto, é que parte deles, para cumprir alguns itens do referido plano, sentiu a necessidade de participar junto à equipe de enfermagem para cuidar do idoso

Posso dizer que agora estou craque, no momento está bem melhor depois de todo o cuidado, é gratificante ver que ele melhorou, pelo menos a pele está ou tra coisa, está melhorando (A16 - sobrinha).

$\mathrm{Na}$ medida em que os acompanhantes dialogaram sobre as características das lesões, começaram a entender os termos relativos a estas que os profissionais utilizavam como: necrose, tecido de granulação, a classificação das úlceras por graus (I, II, III e IV), como também alguns dos produtos utilizados no tratamento como: papaína, Ácidos Graxos Essenciais (AGE), entre outros com as suas indicações. ${ }^{13}$ 
Diante disso, alguns dos acompanhantes conseguiram classificar as úlceras do idoso e relatar as condições da ferida.

Colagenase... Estavam usando ela! Eles tinham dado uma parada nessa pomada para usar o ácido graxo essencial. O que eu observei foi que o verde escuro estava ficando mais clarinho e o verde claro mais branquinho, por isso trocaram a pomada (A5 - filha).

Grau 1 é a daqui... [aponta para região sacra]. Cadê aquela foto que você me mostrou? O de cá tá vermelhinho e tá amarelo, ai a dou tora passou uma pomada que só pode passar lá dentro, a Colagenase. Por fora é o dersani (A3 - cunhada).

No meu cunhado estão passando a papaína porque tem tecido de necrose (A2 - cunhado).

Duas das acompanhantes além de observarem, realizaram curativo simples: uma aplicou AGE em UP grau I e a outra fez o curativo na perna da idosa que estava com erisipela, em conjunto com a enfermeira, inclusive questionando tudo o que estava sendo realizado.

Passei o ácido graxo essencial na úlcera que é grau I, mas eu não massageei passei de leve para a pele não abrir (A13 - filha).

A proposta da pesquisa em tornar o acompanhante partícipe do cuidado ao idoso articulou a experiência da vida prática com a sistematização do conhecimento atendendo aos conceitos da pedagogia freiriana. Conhecimento aqui entendido como uma construção coletiva mediada dialogicamente, através da articulação dialética do saber da experiência feita ${ }^{1}$ (vida prática) com o do técnicocientífico (profissional).

À luz desta discussão, a dialogicidade ganha força no processo de construção do conhecimento, proporcionando a fluência de opiniões, crenças e saberes, refletindo em oportunidades de reflexões e críticas entre os sujeitos. ${ }^{14} \mathrm{~A}$ diversidade de vivências e experiências que emergem deste processo mostra que os acompanhantes são ativos e criativos quando se trata do cuidado em saúde, e devem ser estimulados a saírem da condição passiva ao protagonismo do cuidado de si e do outro que se encontra sob sua responsabilidade.

O compartilhamento de conhecimentos e de ações configurou-se como uma "[...] atitude favorável à autonomia do sujeito (cliente) no cuidado", 15:222 uma vez que o processo de elaboração e de execução do plano de cuidados pelos acompanhantes aconteceu de forma integradora e interativa, permitindo ao acompanhante desco- brir, (re)construir e aplicar seu conhecimento no cuidado ao idoso sob seu acompanhamento.

\section{CONCLUSÃO}

Ao analisar o plano de cuidado pode-se inferir que o diálogo/reflexão permitiu ao acompanhante se instrumentalizar, e ofereceu condições para pensar, refletir criticamente e agir, em busca da participação no cuidado. Identificou-se que não basta reconhecer a existência de um sistema profissional e de um sistema popular de saúde, mas propor estratégias para um cuidado congruente às reais necessidades dos idosos e dos acompanhantes tornando-os parceiros. Nesta pesquisa, esta estratégia utilizou como veículo do cuidado, a educação em saúde pautada no diálogo.

A prevenção e tratamento das UPs se configuraram como um contexto significativo na valorização dos saberes dos acompanhantes e, através do diálogo/reflexão, estes foram mobilizados para conhecer o que não sabiam, sendo estimulados quanto à possibilidade de aplicação de tais saberes. A aprendizagem significativa se concretizou na implementação do plano de cuidados. Cada acompanhante executou o plano lançando mão de suas próprias estratégias, já que pelo diálogo, ele pode se preparar para a intervenção, superando a situação de mero espectador. Percebeu-se que alguns se limitaram a utilizar os recursos que o cenário oferecia, outros improvisaram, buscaram alternativas. Tais comportamentos estiveram presentes tanto no desenvolvimento das ações de prevenção quanto de tratamento das UPs.

Diante das características de atuação dos acompanhantes, as formas de execução do plano foram organizadas considerando as ações para prevenção e tratamento. O processo de elaboração e de execução do plano de cuidados foi integrador e interativo, permitindo a descoberta e (re)construção do conhecimento. Tornar o acompanhante partícipe do cuidado ao idoso articulou a experiência da vida prática com a sistematização do conhecimento científico atendendo aos conceitos da pedagogia freiriana e do cuidado cultural de Leininger. Isto porque possibilitou entender que o conhecimento não é algo dado, mas construído em um processo que implica dialogicidade. Nesse processo, a articulação entre a experiência da vida prática e a ciência contribui para revisões e adaptações importantes para a vida cotidiana.

A associação dos conceitos de Leininger e de Freire mostrou que não basta acessar os saberes 
e práticas dos acompanhantes sobre o tratamento das UPs, identificando seus aspectos culturais, mas reinterpretá-los no processo do diálogo à luz do conhecimento científico. Esse novo saber permitiria ao acompanhante certa autonomia e responsabilidade sobre o cuidado ao idoso.

O resultado alcançado nesta pesquisa mostrou que o cuidado pode ser compartilhado entre equipe de enfermagem e acompanhantes, desde que se compartilhem, também, os saberes de ambos envolvidos neste processo de cuidar. Para tanto, os implicados neste processo - profissional, idoso e acompanhantes/famílias - precisam estar conscientes de que são sujeitos coletivos, ativos e produtores de conhecimento. Nesse sentido, há que se cultivar a dialogicidade e a crítica diante das vivências e experiências diárias em um processo contínuo de educação em saúde junto aos sujeitos do cuidado.

Como contribuição aos fundamentos do cuidado de enfermagem, e a sua epistemologia, esta pesquisa traz ao debate o conceito de cuidado compartilhado amparado nos pressupostos do construcionismo social: o conhecimento se constrói a partir da experiência do sujeito em um processo de significação. Nesse sentido, ao pensarmos que o produto da ação de cuidar (o cuidado) pode ser compartilhado, temos aí, necessariamente, um processo dialógico permeando tal construção no encontro dos saberes - do senso comum e reificado - que, por sua vez, abarca o encontro de culturas de conhecimento e prática. Assim, este conceito de cuidado abrange uma dimensão educativa que implica em mobilização de saberes e afetos, importantes para uma prática solidária e ética para que possa ser verdadeiramente compartilhada.

\section{REFERÊNCIAS}

1. Freire P. Pedagogia do Oprimido. Rio de Janeiro (RJ): Paz e Terra; 1997.

2. Leininger $M$. Transcultural nursing: concepts theories and practice. New York (US): John Wiley; 1978.
3. Trentini M, Paim L. Pesquisa convergenteassistencial: um desenho que une o fazer e o pensar na prática assistencial em saúde-enfermagem. $2^{\mathrm{a}} \mathrm{ed}$. Florianópolis (SC): Insular; 2004.

4. Souza LM, Wegner W, Gorini MIPC. Health education: a strategy of care for the lay caregiver. Rev Latino-am Enfermagem. 2007 Mar-Abr; 15(2):337-43.

5. Vasconcelos MLMC, Brito RHP. Conceitos de educação em Paulo Freire: glossário. Petrópolis/São Paulo (RJ/SP): Vozes/Mack Pesquisa; 2006.

6. Rios ERG, Franchi KMB, Silva RM, Amorim RF, Costa NC. Senso comum, ciência e filosofia: elo dos saberes necessários à promoção da saúde. Ciênc Saúde Colet. 2007 Mar-Abr; 12(2):501-9.

7. Alexandre M. O saber popular e sua influência na construção das representações sociais. Comum. 2000 Ago-Dez; 5(15):161-71.

8. Valla VV. A crise de interpretaçãoénossa: procurando compreender a fala das classes subalternas. Educ Realidade. 1996 Jul-Dez; 21(2):177-91.

9. Boehs AE, Monticelli M, Wosny AM, Heidemann IBS, Grisotti M. A interface necessária entre enfermagem, educação em saúde e o conceito de cultura. Texto Contexto Enferm. 2007 Abr-Jun; 16(2):307-14.

10. Rabeh SAN; Caliri MHL. Prevenção e tratamento de úlceras de pressão: práticas de graduandos de enfermagem. Rev Paul Enferm. 2000; 21(2):133-9.

11. Budó MLD, Saupe R. Modos de cuidar em comunidades rurais: a cultura permeando o cuidado de enfermagem. Texto Contexto Enferm. 2005 AbrJun; 14(2):177-85.

12. Pessanha RV, Cunha FTS. A aprendizagem-trabalho e as tecnologias de saúde na estratégia saúde da família. Texto Contexto Enferm. 2009 Abr-Jun; 18(2):233-40.

13. Mandelbaum SH, Di Santis EP, Mandelbaum MHS. Cicatrização: conceitos atuais e recursos auxiliares. An bras Dermatol. 2003 Set-Out; 78(5):525-42.

14. Trindade WR, Ferreira MA. Grupo feminino de cuidado: estratégia de pesquisa-cuidado à mulher. Rev Bras Enferm. 2009 Maio-Jun; 62(3):374-80.

15. Ferreira MA, Alvim NAT, Teixeira MLO, Veloso RC. Saberes de adolescentes: estilo de vida e cuidado à saúde Texto Contexto Enferm. 2007 Abr-Jun; 16(2):217-24. 